\title{
Dynamics of Intergroup Relationships in Primates: Introduction to the Special Issue
}

\author{
Sarie Van Belle ${ }^{1} \cdot$ Cyril C. Grueter ${ }^{2,3} \cdot$ Takeshi Furuichi $^{4}$
}

Received: 13 March 2020 / Accepted: 14 April 2020 / Published online: 7 May 2020

(C) Springer Science+Business Media, LLC, part of Springer Nature 2020

Intergroup relationships vary greatly among primate species from peaceful intermingling in some species, to the consistent defense of territorial borders in others, to ritualized signaling of resource-holding potential, aggressive stand-offs, or even lethal attacks. They form an integrative part of primate social systems and affect and are affected by male and female reproductive strategies, population density and patterns of intergroup spacing, intergroup communication systems, and dispersal regimes. This special issue is the result of a symposium entitled "Dynamics of Intergroup Relationships in Primates" that we organized during the 27th Congress of the International Primatological Society in Nairobi, Kenya in 2018. The symposium and this special issue aim to explore a broad range of perspectives on intergroup dynamics, including intergroup spacing mechanisms and territoriality, social, and ecological drivers of intergroup conflicts, individual participation in collective group defense, consequences of intergroup interactions on social dynamics, and dispersal patterns. By exploring this across the primate order, this special issue highlights the complexity and diversity of the relationships among social groups and contributes to our comprehension of the relative influences of social, ecological, and genetic factors shaping primate sociality.

Intergroup interactions in primates are behaviorally diverse and span the whole gamut from affiliative or neutral to hostile and even lethal (e.g., Grueter and White 2014; Mirville et al. 2018; Perry 1996; Sommer and Reichard 1997; Wilson et al. 2014). Intergroup conflict is a complex phenomenon involving an interaction between competitive ability, which is affected by group size, and the value of the resources at stake (e.g., mates, territories, or food). Relatedness and familiarity between groups can

Handling Editor: Joanna M. Setchell.

Sarie Van Belle

sarievanbelle@gmail.com

1 Department of Anthropology, University of Texas at Austin, Austin, TX, USA

2 School of Human Sciences, the University of Western Australia, Perth, Australia

3 Centre for Evolutionary Biology, School of Biological Sciences, the University of Western Australia, Perth, Australia

4 Primate Research Institute, Kyoto University, Inuyama, Aichi, Japan 
mediate aggression. All these factors concurrently influence the likelihood, escalation potential, and outcome of intergroup disputes (Cheney 1987; Kitchen and Beehner 2007). Three contributions to this special issue examine variation in the nature of intergroup encounters and their socioecological underpinnings. Cooksey et al. (2020) analyze data from three groups of western lowland gorillas (Gorilla gorilla gorilla). Their main findings are that the likelihood of intergroup interactions decreased with an increasing number of supporting males in the group and that the outcome of these interactions varied in relation to whether the opponent was another group or a solitary male. Their study confirms that mate defense is instrumental in influencing the nature of intergroup encounters in gorillas. Furuichi (2020) reviews the great ape literature and describes variation in intergroup relationships at different levels (between species, between populations, and within populations) and discusses - among other aspectsthe roles males and females play in causing this variation. He emphasizes the importance of peaceful and tolerant encounters, which have not received the academic attention they deserve (cf. Pisor and Surbeck 2019). Hashimoto et al. (2020) follow on from that review and present anecdotal evidence of tolerant intergroup encounters involving female chimpanzees (Pan troglodytes schweinfurthii). They also review reports across subspecies and field sites on chimpanzee encounters involving females and show that those involving a party of one or few females and their offspring were more likely to be peaceful than encounters between mixed-sex or male-only parties of neighboring groups and may provide nulliparous females with opportunities to evaluate other groups for future dispersal. Research into the socioecological drivers underlying intergroup enmity and amity in primates has important implications for an understanding of the evolution of supragroup organization in humans.

The outcome of intergroup encounters can have important effects on space use. Losing intergroup encounters may result in subsequent further or faster travels or in temporal or permanent loss of access to areas surrounding the encounter location (Crofoot 2013; Markham et al. 2012). Such costs, in addition to the risk of physical injuries during intergroup encounters, might lead groups to underuse areas in their home range that overlap with neighboring groups as a strategy to avoid encounters (Wrangham et al. 2007). Other strategies may include confronting rivals when the expected benefits of winning the contest outweigh the costs of losing. Thus, prior to intergroup encounters, groups may use vocal or olfactory cues to obtain information about the current or recent location of neighboring groups and use such information to decide to approach, retreat, or ignore neighbors. Such intergroup spacing mechanisms can result in long-term stable home ranges among adjacent groups. In this special issue, four contributions examine the impact of intergroup relationships on long-term spatial use, as well as movement patterns prior to intergroup encounters. Bonadonna et al. (2020) analyze home range and core area stability of three contiguous groups of indris (Indri indri). Over the 5-year study, home ranges were mostly stable, yet shifts in the home range location of one group caused corresponding shifts in a neighboring group in order to maintain spatial exclusivity of their defended territories. Tórrez-Herrera et al. (2020) examine whether white-faced capuchins (Cebus capucinus) alter their behaviors at the periphery of their home ranges, areas that are underused potentially because of the costs and risks associated with intergroup encounters. They found that capuchins did not adjust their foraging behavior as predicted. Instead, they visited Attalea butyracea trees at the periphery of their ranges for longer, ate more fruits, and 
depleted these trees more fully than trees in the central area of the home range, suggesting that foraging benefits outweighed the potential costs and perceived risks of intergroup encounters. Van Belle and Estrada (2020) found that black howler monkey (Alouatta pigra) groups encountered neighboring groups more often than would be expected by chance, and that they were more likely to move toward recent calls of nearby but out-of-sight neighboring groups, particularly when fruits were scarce, suggesting that they were more willing to confront their opponents when important resources were limited. Similarly, Brown (2020) studies the movement responses of individual gray-cheeked mangabeys (Lophocebus albigena) to natural or simulated loud calls of out-of-sight neighboring groups. Males approached more frequently than females, yet all individuals tended to retreat when the neighbors were close by $(<500 \mathrm{~m})$.

The initiation of an intergroup contest, the level of aggression during the contest, and the contest outcome is mediated by asymmetries between rival groups in their fighting abilities (i.e., resource-holding potential) and the expected payoffs if they were to win the encounter (Arnott and Elwood 2009; Maynard Smith 1974; Parker 1974). The difference in group size is commonly used as a proxy for asymmetries in groups' competitive abilities, yet the number of participants or the fighting ability of particular group members may be a better predictor of intergroup encounter aggression (Harris 2010; Van Belle and Scarry 2015; Zhao and Tan 2011; for a human example see Grueter et al. 2016). Participative behaviors of group members may vary across age, sex, social status, and dominance rank, and according to the expected payoffs of winning the contest (Arseneau-Robar et al. 2017; Crofoot et al. 2008; Fashing 2001; Van Belle et al. 2014). Furthermore, natural selection should favor individuals that refrain from participating in intergroup encounters and therefore incur no costs, yet reap the benefits of the defensive actions by other group members, known as the "collective action problem" (Nunn 2000; Nunn and Lewis 2001). In this special issue, Majolo et al. (2020) examine these effects by comparing the findings from 52 studies on 31 primate species. They found that larger groups are more likely to win encounters against smaller groups, but found no effects of age, dominance rank, and sex of individuals on the level of aggressive behaviors individuals displayed. They suggest that the lack of support for the effects of these individual traits may be due to differences in species-specific strategies employed by different group members. Indeed, their analyses show that some species showed positive while others showed negative impacts of sex on frequency of aggressive participation in intergroup encounters. Brown's (2020) study on gray-cheeked mangabeys' movement responses to loud calls of neighboring groups shows that males and females in smaller groups were more likely to move away, while individuals in larger groups both approached and retreated, consistent with the hypothesis that numerical superiority evokes higher group-level resource-holding potential (Kitchen and Beehner 2007). In contrast, Lewis et al. (2020) show that, in Verreaux's sifakas (Propithecus verreauxi), larger groups were not more likely to supplant smaller groups. Tendencies to participate largely differed by sex, with males being the primary participants, likely representing defense of mating opportunities with resident females. Females more likely participated in encounters during the lactation season when food resources were scarce.

Intergroup conflict (or intergroup competition more generally) can bring about behavioral consequences in group members, which unfold over the short and long 
term. Some of these consequences include changes in group cohesion and social relationships, which can have significant fitness consequences (Lemoine et al. 2020; Majolo et al. 2016). The link between intergroup conflict and intragroup affiliation in primates was first explicitly explored by Cheney (1992) but then research on this topic remained dormant until a surge of interest in recent years, which was at least partly motivated by work in the human behavioral sciences (Puurtinen and Mappes 2009; Rusch 2014; Sherif et al. 1961). The available evidence for an effect of intergroup conflict on intragroup cohesion in primates is mixed (e.g., Grueter 2013; Majolo et al. 2016); disagreement in the literature indicates that various modulating factors may be at play such as the social system, conflict characteristics and conflict outcome, and familiarity between opposing groups (for a review see Radford et al. 2016). Three articles in this special issue examine this topic: Samuni et al. (2020) collected data on two communities of chimpanzees (Pan troglodytes verus), and show associations between border patrols and intergroup encounters and several measures of in-group cohesion, i.e., modularity, party size, and intragroup aggression. Yi et al. (2020) examine behavioral responses to intergroup aggression in territorial, pair-living Javan gibbons (Hylobates moloch) and found changes in activity budgets and sleeping tree locations; contrary to their prediction, pairs groomed less in the hour post-encounter than in the matched-control period. Mirville et al. (2020) compare the proximity patterns, activity budgets, and affiliative behavior of mountain gorilla (Gorilla beringei beringei) group members before and after aggressive intergroup interactions. Their results show that responses are not that clear-cut but modulated by familiarity, conflict outcome, and sex. These articles enhance our understanding of the interplay between intergroup conflict and intragroup behavioral consequences and will undoubtedly stimulate further empirical research in this space.

Dispersal regimes, particularly transfer between neighboring groups, can influence intergroup relationships, as familiarity and relatedness between groups may mediate aggression (Bradley et al. 2004; Cooksey et al. 2020). Additionally, intergroup encounters may provide opportunities to individuals of the dispersing sex to gain information about potential dispersal opportunities (Hashimoto et al. 2020), or transfer may occur only during intergroup encounters (Furuichi 2020; Sicotte 1993). Two contributions to this issue deal with genetic and behavioral correlates of intergroup transfer of females in a wild bonobo (Pan paniscus) population. Ishizuka et al. (2020) examine the proportion of transfers of females from their natal group to a neighboring group by both observational and genetic analyses. Their findings indicate that around $60 \%$ of females transfer to a neighboring group and settle there to reproduce, suggesting that female bonobos do not disperse far from their natal groups because they usually transfer between groups during peaceful intergroup encounters. Toda and Furuichi (2020) examine aggression from resident females toward immigrant females, and show that the rate of aggression against immigrant females was low and decreased with age in resident females, probably because older females are higher in dominance rank and suffer from little food competition with immigrant females. These tendencies of transfer to neighboring groups during peaceful encounter and social tolerance of resident females to immigrant females may explain the fact that female bonobos leave their natal group at a younger age than do female chimpanzees (Sakamaki et al. 2015).

The contributions to this special issue and relevant citations therein demonstrate the complexity of intergroup relationships in primates, and the variation among species, 
among populations of the same species, among pairs of groups within a population, and within pairs of groups over time. With this special issue, we emphasize the great variety of aspects associated with intergroup relationships that may be studied. We end with a series of research questions that we deem critical to the study of dynamics of intergroup relationships in primates:

1. What are the immediate, short-term, and long-term benefits or costs of winning or losing intergroup encounters? What demographic, social, physiological, and ecological factors underlie these costs and benefits?

2. What are the selective incentives for tolerant and cooperative interactions between individuals residing in different groups (e.g., reconnaissance before transfer, extragroup mating, and enhanced food procurement)? How does intergroup tolerance vary in relation to characteristics of and relationships between the interactants and socioecological circumstances?

3. How do individuals differ in their post-intergroup conflict behavioral response, and how are differences affected by individual contribution to conflict, opponent identity, and resources at stake?

4. How do group members overcome collective action problems during intergroup defense? Which mechanisms underlie individuals' participation patterns (e.g., kin selection, byproduct mutualism, punishment), and how do these mechanisms differ with social systems?

5. Can measurements of relative group-level resource-holding potential that reflect the number of participants, the amount each participates, or participants' fighting abilities better predict the initiation of intergroup contests, the level of aggression during contest, or contest outcome than does relative group size, a commonly used proxy for group-level competitive ability?

6. Do loud calls that are hypothesized to play a role in intergroup communication mediate movement decisions of listening groups and thus impact intergroup spacing mechanisms?

7. How do intergroup conflicts influence large-scale patterns of space partitioning between groups within a habitat? Do gradual or abrupt shifts in a group's home range cause corresponding shifts in neighboring groups? Does this effect differ between territorial and nonterritorial primate species?

Answering these questions across many primate species will move forward the field of primate behavioral ecology by considering the relationships between neighboring social groups as a core component of the social structure in describing primate species' social systems (sensu Kappeler 2019).

Acknowledgements We thank Jo Setchell for her support in making this special issue come true, as well as all persons who reviewed manuscripts submitted to this special issue: Jean Arseneau-Robar, Filippo Aureli, Norberto Asensio, Thad Bartlett, Michelle Brown, Leveda Cheng, Giovanni Forcina, Catherine Hobaiter, Ingrid Holzmann, Adrian Jaeggi, Lydia Light, Bonaventura Majolo, Alex Mielke, John Mitani, Liza Moscovice, Kevin Langergraber, Andrea Presotto, Martha Robbins, Stacy Rosenbaum, Tetsuya Sakamaki, Aaron Sandel, Hiroki Sato, Clara Scarry, Yuji Takenoshita, Erik Willems, and Michael Wilson. We are also grateful to all the participants of our symposium at the meeting of the International Primatological Society, held on August 19-25, 2018 in Nairobi, Kenya, for their excellent presentations, constructive comments, and discussions. 


\section{References}

Arnott, G., \& Elwood, R. W. (2009). Assessment of fighting ability in animal contests. Animal Behaviour, 77, 991-1004.

Arseneau-Robar, T. J. M., Taucher, A. L., Schnider, A. B., van Schaik, C. P., \& Willems, E. P. (2017). Intraand interindividual differences in the costs and benefits of intergroup aggression in female vervet monkeys. Animal Behaviour, 123, 129-137.

Bonadonna, G., Zaccagno, M., Torti, V., Valente D., De Gregorio, C., et al. (2020). Intra- and intergroup spatial dynamics of a pair-living singing primate, Indri indri: A multiannual study of three indri groups in Maromizaha Forest, Madagascar. International Journal of Primatology, 41(2). https://doi.org/10.1007 /s10764-019-00127-5.

Bradley, B. J., Doran-Sheehy, D. M., Lukas, D., Boesch, C., \& Vigilant, L. (2004). Dispersed male networks in Western gorillas. Current Biology, 14, 510-513.

Brown, M. (2020). Detecting an effect of group size on individual responses to neighboring groups in greycheeked mangabeys (Lophocebus albigena). International Journal of Primatology, 41(2). https://doi. org/10.1007/s10764-020-00144-9.

Cheney, D. L. (1987). Interactions and relationships between groups. In B. B. Smuts, D. L. Cheney, R. M. Seyfarth, \& R. Wrangham (Eds.), Primate societies (pp. 267-281). Chicago: University of Chicago Press.

Cheney, D. L. (1992). Intragroup cohesion and intergroup hostility: The relation between grooming distributions and intergroup competition among female primates. Behavioral Ecology, 3, 334-345.

Cooksey, K., Sanz, C., Ebombi, T. F., Massamba, J. M., Tebard, P., et al. (2020). Socioecological factors influencing intergroup encounters in western lowland gorillas (Gorilla gorilla gorilla). International Journal of Primatology, 41(2). https://doi.org/10.1007/s10764-020-00147-6.

Crofoot, M. C. (2013). The cost of defeat: Capuchin groups travel further, faster and later after losing conflicts with neighbors. American Journal of Physical Anthropology, 152, 79-85.

Crofoot, M. C., Gilby, I. C., Wikelski, M., \& Kays, R. (2008). Interaction location outweighs the competitive advantage of numerical superiority in Cebus capucinus intergroup contests. Proceedings of the National Academy of Sciences of the USA, 105, 577-581.

Fashing, P. J. (2001). Male and female strategies during intergroup encounters in guerezas (Colobus guereza): Evidence for resource defense mediated through males and a comparison with other primates. Behavioral Ecology and Sociobiology, 50, 219-230.

Furuichi, T. (2020). Variation in intergroup relationships among species and among and within local populations of African apes. International Journal of Primatology, 41(2). https://doi.org/10.1007 /s10764-020-00134-x.

Grueter, C. C. (2013). No effect of inter-group conflict on within-group harmony in non-human primates. Communicative and Integrative Biology, 6, e26801.

Grueter, C. C., \& White, D. R. (2014). On the emergence of large-scale human social integration and its antecedents in primates. Structure and Dynamics, 7, 1-27 https:/escholarship.org/uc/item/2569z15g.

Grueter, C. C., Johnson, L., Leaning, M., Tan, M. J., Jones, Z., \& Peris, J. (2016). An evolutionary view of conflict escalation in team sports competitions. Human Ethology Bulletin, 31, 45-51.

Harris, T. R. (2010). Multiple resource values and fighting ability measures influence intergroup conflict in guerezas (Colobus guereza). Animal Behaviour, 79, 89-98.

Hashimoto, C., Isaji, M., Mouri, K., \& Takemoto, H. (2020). Intergroup encounters of chimpanzees: From the female perspective. International Journal of Primatology, 41(2). https://doi.org/10.1007/s10764-02000145-8.

Ishizuka, S., Toda, K., \& Furuichi, T. (2020). Genetic analysis of migration pattern of female bonobos (Pan paniscus) among three neighboring groups. International Journal of Primatology, 41(2). https://doi. org/10.1007/s10764-019-00106-w.

Kappeler, P. M. (2019). A framework for studying social complexity. Behavioral Ecology and Sociobiology, $73,13$.

Kitchen, D., \& Beehner, J. (2007). Factors affecting individual participation in group-level aggression among non-human primates. Behaviour, 144, 1551-1581.

Lemoine, S., Preis, A., Samuni, L., Boesch, C., Crockford, C., et al (2020). Between-group competition impacts reproductive success in wild chimpanzees. Current Biology, 30, 1-7.

Lewis, R., Sandel, A., Hilty, S., \& Barnett, S. E. (2020). The collective action problem but not numerical superiority explains success in intergroup encounters in Verreaux's sifaka (Propithecus verreauxi): Implications for individual participation and free-riding. International Journal of Primatology, 41(2). https://doi.org/10.1007/s10764-020-00155-6. 
Majolo, B., de Bortoli Vizioli, A., \& Lehmann, J. (2016). The effect of intergroup competition on intragroup affiliation in primates. Animal Behaviour, 114, 13-19.

Majolo, B., deBortoli Vizioli, A., Martínez-Íñigo, L., \& Lehmann, J. (2020). Effect of group size and individual characteristics on intergroup encounters in primates. International Journal of Primatology, 41(2). https://doi.org/10.1007/s10764-019-00119-5.

Markham, A. C., Alberts, S. C., \& Altmann, J. (2012). Intergroup conflict: Ecological predictors of winning and consequences of defeat in a wild primate population. Animal Behaviour, 84(2), 399-403.

Maynard Smith, J. (1974). The theory of games and the evolution of animal conflicts. Journal of Theoretical Biology, 47, 209-221.

Mirville, M. O., Ridley, A. R., Samedi, J. P. M., Vecellio, V., Ndagijimana, F., et al (2018). Low familiarity and similar 'group strength' between opponents increase the intensity of intergroup interactions in mountain gorillas (Gorilla beringei beringei). Behavioral Ecology and Sociobiology, 72, 178.

Mirville, M. O., Ridley, A. R., Samedi, J. P. M., Vecellio, V., Ndagijimana, F., et al. (2020). Intragroup behavioral changes following intergroup conflict in mountain gorillas (Gorilla beringei beringei). International Journal of Primatology, 41(2). https://oi.org/10.1007/s10764-020-00130-1.

Nunn, C. L. (2000). Collective benefits, free-riders, and male extra-group conflict. In P. Kappeler (Ed.), Primate males: Causes and consequences of variation in group composition (pp. 192-204). Cambridge: Cambridge University Press.

Nunn, C. L., \& Lewis, R. J. (2001). Cooperation and collective action in animal behaviour. In R. Noë, J. A. R. A. M. van Hooff, \& P. Hammerstein (Eds.), Economics in nature: Social dilemmas, mate choice and biological markets (pp. 42-66). Cambridge: Cambridge University Press.

Parker, G. (1974). Assessment strategy and the evolution of fighting behavior. Journal of Theoretical Biology, 47, 223-243.

Perry, S. (1996). Intergroup encounters in wild white-faced capuchins (Cebus capucinus). International Journal of Primatology, 17, 309-330.

Pisor, A. C., \& Surbeck, M. (2019). The evolution of intergroup tolerance in nonhuman primates and humans. Evolutionary Anthropology, 28, 210-223.

Puurtinen, M., \& Mappes, T. (2009). Between-group competition and human cooperation. Proceedings of the Royal Society B: Biological Sciences, 276, 355-360.

Radford, A. N., Majolo, B., \& Aureli, F. (2016). Within-group behavioural consequences of between-group conflict: A prospective review. Proceedings of the Royal Society B: Biological Sciences, 283, 20161567.

Rusch, H. (2014). The evolutionary interplay of intergroup conflict and altruism in humans: A review of parochial altruism theory and prospects for its extension. Proceedings of the Royal Society B: Biological Sciences, 278, 20141539.

Sakamaki, T., Behncke, I., Laporte, M., Mulavwa, M., Ryu, H., et al (2015). Intergroup transfer of females and social relationships between immigrants and residents in bonobo (Pan paniscus) societies. In T. Furuichi, F. Aureli, \& J. Yamagiwa (Eds.), Dispersing primate females (pp. 127-164). Tokyo: Springer Science+ Business Media.

Samuni, L., Mielke, A., Preis, A., Crockford, C., \& Wittig, R. M. (2020). Intergroup competition enhances chimpanzee (Pan troglodytes verus) in-group cohesion. Journal of Primatology, 41(2). https://doi. org/10.1007/s10764-019-00112-y.

Sherif, M., Harvey, O. J., White, B. J., Hood, W. R., \& Sherif, C. (1961). Inter-group conflict and cooperation: The Robbers Cave experiment. Norman, OK: University of Oklahoma Press.

Sicotte, P. (1993). Inter-group encounters and female transfer in mountain gorillas: Influence of group composition on male behavior. American Journal of Primatology, 30, 21-36.

Sommer, V., \& Reichard, U. (1997). Group encounters in wild gibbons (Hylobates lar): Agonism, affiliation, and the concept of infanticide. Behaviour, 134, 1135-1174.

Toda, K., \& Furuichi, T. (2020). Low resistance of senior resident females toward female immigration in bonobos (Pan paniscus) at Wamba, Democratic Republic of the Congo. International Journal of Primatology, 41(2). https://doi.org/10.1007/s10764-019-00126-6.

Tórrez-Herrera, L. L., Davis, G. H., \& Crofoot, M. C. (2020). Do monkeys avoid areas of home range overlap because they are dangerous? A test of the risk hypothesis in white-faced capuchin monkeys (Cebus capucinus). International Journal of Primatology, 41(2). https://doi.org/10.1007/s10764-019-00110-0 .

Van Belle, S., \& Estrada, A. (2020). The influence of loud calls on intergroup spacing mechanism in black howler monkeys (Alouatta pigra). International Journal of Primatology, 41(2). https://doi.org/10.1007 /s10764-019-00121-x .

Van Belle, S., \& Scarry, C. J. (2015). Individual participation in intergroup contests is mediated by numerical assessment strategies in black howler and tufted capuchin monkeys. Philosophical Transactions of the Royal Society B: Biological Sciences, 370, 20150007. 
Van Belle, S., Garber, P. A., Estrada, A., \& Di Fiore, A. (2014). Social and genetic factors mediating male participation in collective group defence in black howler monkeys. Animal Behaviour, 98, 7-17.

Wilson, M., Boesch, C., Fruth, B., et al (2014). Lethal aggression in Pan is better explained by adaptive strategies than human impacts. Nature, 513, 414-417.

Wrangham, R., Lundy, R., Crofoot, M., \& Gilby, I. (2007). Use of overlap zones among group-living primates: A test of the risk hypothesis. Behaviour, 144, 1599-1619.

Yi, Y., Fichtel, C., Kim, E., \& Choe, J. C. (2020). Impacts of intergroup interactions on intragroup behavioral changes in Javan gibbons (Hylobates moloch). International Journal of Primatology, 41(2). https://doi. org/10.1007/s10764-019-00116-8.

Zhao, Q., \& Tan, C. L. (2011). Inter-unit contests within a provisioned troop of Sichuan snub nosed monkeys (Rhinopithecus roxellana) in the Qinling Mountains, China. American Journal of Primatology, 73, 262269. 